\title{
OBTENÇÃO DE FERMENTO A PARTIR DO CULTIVO DE LEVEDURAS SELVAGENS ORIUNDAS DA BATATA INGLESA
}

Luiz Henrique Fernandes da Silva, Angela Cristina Gomes, Dionilso Osvaldo Fiori Júnior, Rogério Giuffrida.

ETEC Prof. Dr. Antônio Eufrásio de Toledo, Curso de Agroindústria, Presidente Prudente, SP. E-mail: luiz.silvaa4@gmail.com

\section{RESUMO}

Considerado um alimento barato e energético, o pão faz parte da gastronomia de diversas culturas. Em sua fabricação se faz uso de processo fermentativo e, é nesta atividade que a fermentação natural é posta em dúvida quanto a sua sanitariedade e padrões fermentativos, sendo desta forma, trocado pelo fermento biológico comercial. O objetivo deste estudo foi caracterizar a produção de fermento natural pela fermentação da batata inglesa com microrganismos indígenas do tubérculo. A metodologia para fabricação do fermento foi baseada em saberes empíricos e a identificação dos tipos de microrganismos foi realizada com análises microbiológicas para contagem de leveduras, coliformes fecais e totais, Staphylococcus aureus e Salmonella. Os resultados demonstraram a utilização da batata como base fermentativa e as análises excluíram os microrganismos patogênicos pesquisados, visto que apenas leveduras e bactérias mesófilas comuns ao meio foram identificadas. Desta forma, os resultados sugerem que o processo artesanal não trás problemas com relação à sanitariedade do produto final, além de propiciar um valoroso resgaste histórico culinário cultural.

Palavras-chave: Batata Inglesa, Fermento Biológico, Fermentação Natural, Leveduras, Pão.

\section{OBTAINING DERIVATION FROM THE WILD YEAST CULTIVATION FROM THE ENGLISH POTATO}

\begin{abstract}
Considered a cheap and very energetic food, bread is part of the gastronomy of various cultures. In its manufacture it is made use of fermentative process and it is in this activity that the natural fermentation is put in doubt as to its sanitary and fermentative standards, being changed then by the commercial biological yeast. The objective of this study was characterized by the production of natural yeast through the fermentation of the English potato with microorganisms present in the tuber itself. The methodology for the production of yeast was based on empirical knowledge and the identification of the types of microorganisms through microbiological analyzes. The results demonstrated the use of the potato as a fermentation base and the analyzes excluded pathogenic microorganisms, verifying the presence of yeasts and mesophilic bacteria common to the medium. Thus, it is possible to emphasize that this artisanal process does not present problems with regard to the sanity of the final product, in addition to providing a valuable historical cultural culinary heritage.
\end{abstract}

Keywords: Potato, Biological Yeast, Natural Fermentation, Yeast, Bread 


\section{INTRODUÇÃO}

A fermentação é uma técnica milenar, sendo possível constatar sua atuação até mesmo nos registros antigos da terra como, por exemplo, as Sagradas Escrituras (Bíblia), onde no Livro de Mateus, capítulo 13 e versículo 33, lê-se“... O reino dos céus é semelhante ao fermento, que uma mulher toma e introduz em três medidas de farinha, até que tudo esteja levedado...", ou no Livro de Gálatas, capítulo 5 e versículo 9, que destaca “...Um pouco de fermento leveda toda a massa...", assim, ambos os trechos ressaltam a atividade da levedura mediante a um substrato, e nota-se um pensamento empírico, ou seja, não comprovado cientificamente na época em que fora escrito (ALMEIDA, 2011).

Mas Lacaz (1970) e Lacaz (1991) destacam que as primeiras ideias cientificas a respeito da intervenção dos fungos, veio com Krunitz, em 1775, que definiu as leveduras como "... corpos que existem durante a fermentação...". Sendo que Lavoisier em 1789 comprovou que nesses processos ocorrem reações bioquímicas, com produção de álcool etílico $\left(\mathrm{CH}_{3} \mathrm{CH}_{2} \mathrm{OH}\right)$ e dióxido de carbono $\left(\mathrm{CO}_{2}\right)$.

Venquiaruto et. al. (2011), afirma que, antes dos fermentos químicos e biológicos, fazia-se uso dos fermentos naturais. As receitas, não tão precisas, foram passadas de geração em geração, sem entender o que se sucedia. Contudo, com estudos aprofundados, foi possível perceber que alguns microrganismos são responsáveis por esse processo fermentativo, com destaque para a levedura Saccharomyces cerevisiae, utilizada tanto na fermentação de bebidas alcoólicas como no setor de panificação.

Oliveira (2015) ressalta que esta descoberta, ou melhor, "constatação" foi muito benéfica para a indústria panificadora, pois a mesma faz o uso da biotecnologia (uso de células ou sistemas bioquímicos) para produção de pães e afins, sofrendo processo de evolução tecnológica contínuo, porém o microrganismo utilizado ainda é a Saccharomyces cerevisiae, ou seus derivados.

Com sua origem na Cordilheira dos Andes, a batata inglesa pertence à família Solanaceae, do gênero Solanum, espécie Solanum tuberosum L., no Brasil, é a tuberosa de maior importância, a qual obteve somente no ano de 2017, produtividade superior a 4 milhões de toneladas (IBGE, 2018), setor este em franca expansão posto que em 2006 a produção foi próxima a 3,5 milhões de toneladas (EMBRAPA, 2016).

$\mathrm{Na}$ batata inglesa, os microrganismos fermentescíveis estão presentes na casca, sendo em grande parte leveduras caracterizadas como "selvagens". Dessa maneira, quando inseridas em caldo nutritivo (substrato), esses microrganismos tendem a se desenvolver, iniciando o processo metabólico fermentativo.

A batata possui alto valor nutricional e cerca de $20 \%$ do peso em carboidratos, sendo um produto de extrema importância para elaboração do fermento natural (LEONEL \& CEREDA, 2002).

Para Aplevicz (2014), o pão, está presente nas manhãs de quase toda população brasileira, (76\%) sendo que dentro deste valor $14 \%$ são industrializados e $86 \%$ são artesanais. A popularidade estimula o empenho para geração de novas fórmulas e novos produtos para o processamento de pães (ZAKABI, 2006; SEBRAE E ABIP, 2009).

No Brasil a indústria de panificação está entre os seis maiores segmentos industriais e, atualmente, busca novos desafios tecnológicos que permitam sua afirmação definitiva como setor de relevância no cenário econômico (SEBRAE E ABIP, 2009).

Dessa forma, este cenário traz oportunidades de desenvolvimento e com esta perspectiva, o presente estudo intuita-se em verificar uma alternativa para fermentação natural à base de batata inglesa, analisando o desenvolvimento microbiológico, além de características do processo e do produto final, que neste caso é o próprio pão a fim de trazer uma nova ótica à técnica, agregando valores científicos aos conhecimentos empíricos e agregar maior qualidade ao produto oferecido, além do resgate histórico culinário cultural. 


\section{METODOLOGIA}

Para a construção deste estudo, foi realizado levantamento bibliográfico através de livros, revistas e bases científicas eletrônicas da Scientific Electronic Library Online (SCIELO) e Google Acadêmico, já que foi necessário conhecimento popular sobre as receitas de fermentos naturais.

O estudo foi desenvolvido na Escola Técnica Prof. Dr. Antônio Eufrásio de Toledo. Após a obtenção das informações via pesquisa bibliográfica, as mesmas foram utilizadas para orientação da execução do trabalho, no qual se fabricou o fermento natural à base de batata inglesa e o produto final "pão", em seguida utilizou-se de análises microbiológicas para verificação dos microrganismos presentes no fermento, estas foram realizadas conforme normas oficialmente recomendadas pelo Ministério da Agricultura (BRASIL, 2003).

\section{Procedimento Para Preparação Do Fermento}

O fermento foi elaborado com a mistura de $35 \mathrm{~g}$ de açúcar cristal branco, com a polpa ralada de uma batata inglesa média, ao qual se introduziu $400 \mathrm{~mL}$ de água. Essa mistura foi transferida para uma garrafa com rolha e descansou por 72 horas a temperatura ambiente, que oscilou entre 20 e $40^{\circ} \mathrm{C}$ (CIIAGRO - UNOESTE, 2018).

O fermento foi monitorado até que a massa da batata apresentar densidade menor que a da água, provavelmente pelos gases produzidos, assim com a presença da massa sobrenadante, indicativos de que estava no momento de realizar a "reforma do fermento". Esta se procedeu separando o líquido da massa pelo escoamento com peneira. Do líquido resultante foi retirado $250 \mathrm{~mL}$ aos quais juntou-se mais $250 \mathrm{~mL}$ de água e novamente a polpa de mais uma batata inglesa média e a mesma quantidade de açúcar (35 g). A mistura formada foi novamente acomodada em recipiente de vidro (garrafa) com rolha. Esse processo foi realizado mais duas vezes. Caso não seja utilizado o fermento deve ser armazenado em geladeira por no máximo sete dias sem realizar a reforma.

Para utilização na panificação, o fermento deve ser reformado no dia em que se deseja iniciar a fabricação, assim é necessário deixa-lo em temperatura ambiente e reformá-lo novamente, o indicativo de que o mesmo encontra-se pronto é o "o teste do balão na garrafa adaptado". Venquiaruto et al. (2011), destaca que a cinética-química, nada mais é que o efeito das reações químicas influenciadas pela temperatura, ou seja, que os fermentos de caráter biológico devem passar por um teste denominado "teste do balão na garrafa", no qual corresponde a inserção de um balão na boca de uma garrafa para verificação da produtividade de $\mathrm{CO}_{2}$ (dióxido de carbono), acreditando-se que quando "encher" significativamente o balão, caracteriza-se o ponto de maturação do fermento e ele estará pronto para uso.

Diante desse contexto, para o desenvolvimento do fermento em questão foram realizadas algumas adaptações e no lugar do balão foi introduzida uma rolha para que quando estivesse no ápice do seu desenvolvimento, este desprenderia com força indicando que o fermento estava "pronto" para uso (FIGURA 1B).

Para a confirmação da eficiência do fermento, foi produzido o pão utilizando receita básica e comum, a qual utiliza um quilo de farinha, 1 ovo, $50 \mathrm{~mL}$ de óleo, $5 \mathrm{~g}$ sal e $35 \mathrm{~g}$ de açúcar.

\section{Procedimento Para Análises Microbiológicas Preparo dos inóculos}

Para a realização das culturas microbianas, o caldo de fermentação foi diluído em água peptonada tamponada nas diluições $10^{-1}, 10^{-2}$ e $10^{-3}$, com auxílio de pipeta estéril.

\section{Cultura de Salmonella}

Foram retirados do fermento, 0,1 e $1 \mathrm{ml}$ do caldo de fermentação pura, para inoculação nos caldos e Rappaport-Vassiliadis e Tetrationato de Sódio, respectivamente, visando o 
enriquecimento seletivo para Salmonella. Após 18 horas de incubação a $35 \pm 2{ }^{\circ} \mathrm{C}$, foram retiradas alíquotas dos meios para semeadura agar Rambach. Após 24 de incubação a $35 \pm 2{ }^{\circ} \mathrm{C}$, as placas foram examinadas para pesquisa de colônias de cor rosa-clara ou avermelhadas, compatíveis com Salmonella.

\section{Contagem de mesófilos totais}

De cada diluição, retirou-se $0,1 \mathrm{ml}$ para cultura superficial em placas de agar padrão de contagem. Após incubar as placas por 24 horas, as colônias bacterianas foram enumeradas e os valores expressos em Unidades Formadoras de Colônia por ml de fermento.

\section{Contagem de Coliformes fecais termotolerantes}

Foi realizado procedimento idêntico ao anterior, contudo utilizando-se Agar Eosina Azul de Metileno para contagem de coliformes fecais termotolerantes.

\section{Contagem de Coliformes totais}

Foi realizado procedimento idêntico ao anterior, contudo utilizando-se Agar MacConkey para contagem de coliformes totais.

\section{Cultura de fungos e leveduras}

Foi realizado procedimento idêntico ao anterior, contudo utilizando-se Agar Batatadextrose para contagem de bolores e leveduras.

\section{RESULTADOS}

\section{Obtenção Do Fermento De Batata Inglesa}

Após a fabricação do fermento foram realizadas reformas do mesmo para estímulo do desenvolvimento microbiano totalizando três, sendo a primeira iniciada com 24 horas após a fabricação do fermento, a segunda com 48 horas e a terceira e última com 72 horas. Após esse procedimento o fermento estava apto para a panificação. A Figura 1A destaca o fermento após o preparo e após o teste do balão adaptado (FIGURA 1B).

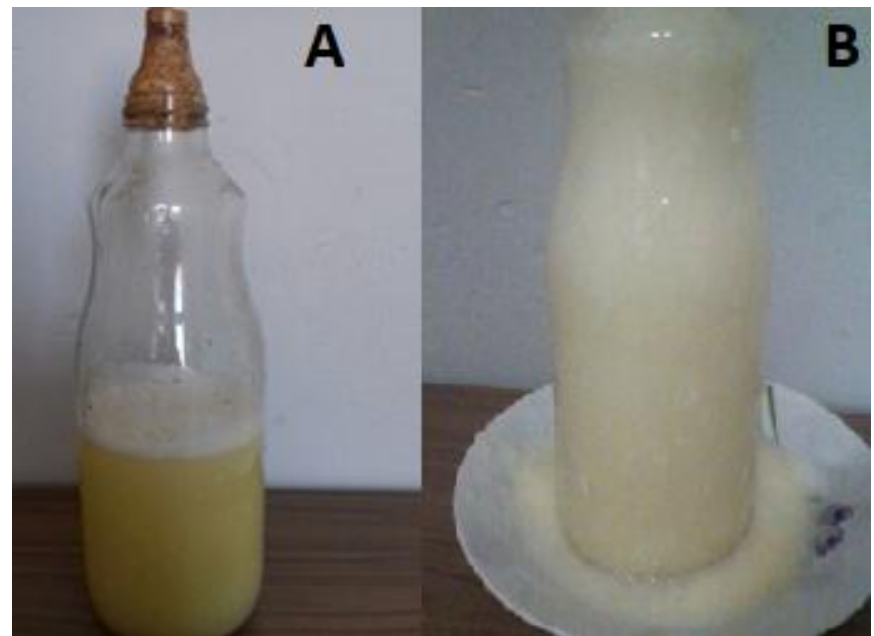

Figura 1. Fermento de batata inglesa (A), teste do balão adaptado (B)

Fonte: Os autores, 2018.

\section{Fabricação De Pão Com Fermento Natural De Batata Inglesa}

A Tabela 2 destaca o tempo de desenvolvimento da massa de pão correspondente ao seu diâmetro, sendo possível visualizar as características desta massa na Figura 2. 
Tabela 2. Tempo de desenvolvimento do pão com fermento de batata inglesa

\begin{tabular}{|c|c|}
\hline Tempo de desenvolvimento $(\mathbf{h})$ & Diâmetro da massa $(\mathbf{c m})$ \\
\hline $\mathbf{0 0 : 0 0}$ & 18 \\
$\mathbf{0 4 : 0 0}$ & 20 \\
$\mathbf{0 8 : 0 0}$ & 26 \\
$\mathbf{1 2 : 0 0}$ & 35 \\
$\mathbf{1 4 : 0 0}$ & 33 \\
\hline
\end{tabular}

Fonte: Os autores, 2018.

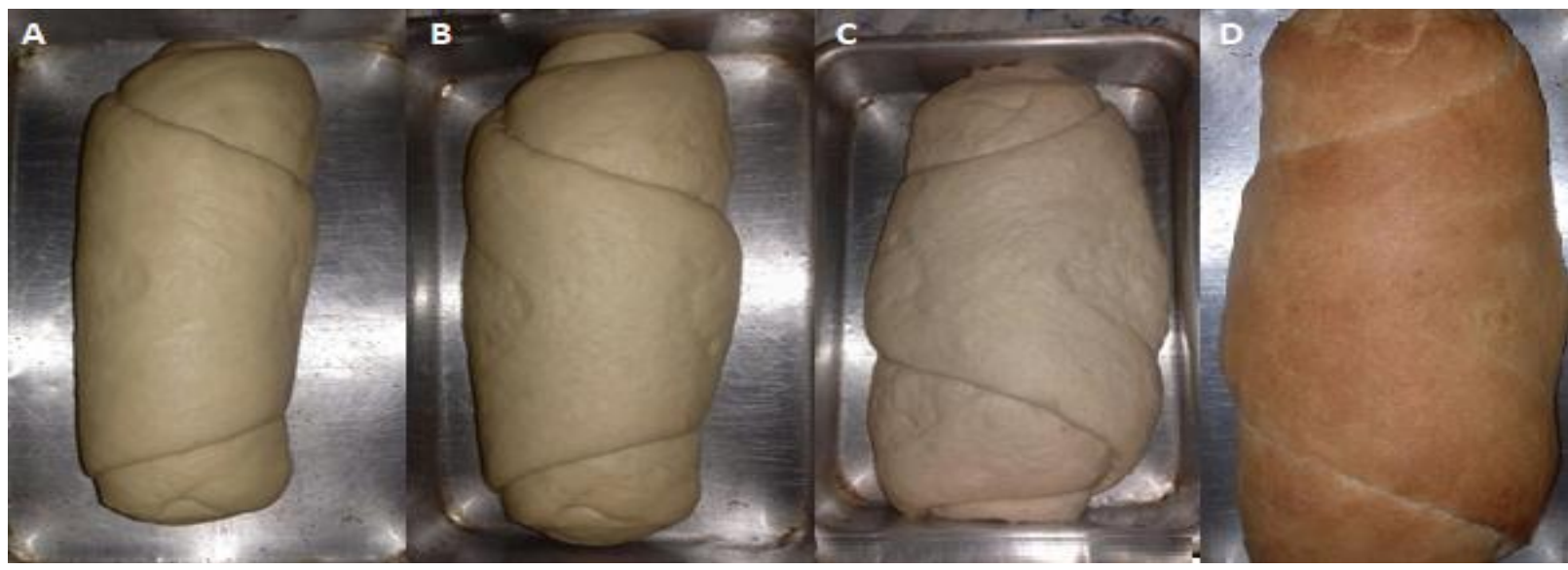

Figura 2. Fases de crescimento do pão feito com fermento de batata inglesa

Fonte: Os autores, 2018.

\section{Análises Microbiológicas Do Fermento de Batata Inglesa}

Para as análises microbiológicas os resultados encontrados foram:

a.) Pesquisa de Salmonella: negativo

b.) Contagem de bolores: negativo

c.) Contagem de coliformes fecais: negativo

d.) Contagem de mesófilos totais: $1200 \mathrm{UFC} / \mathrm{ml}$

e.) Contagem de leveduras: 650 x 10(5) céls $/ \mathrm{ml}$

Levedura identificada: Sacharomyces cerevisae

\section{DISCUSSÃO}

\section{Obtenção Do Fermento De Batata Inglesa}

VENQUIARUTO, et al. (2011), explica que para um volume de um litro de fermento podem ser preparados uma massa com três quilos de farinha. Essa quantidade de fermento natural, corresponde a 3 colheres de sopa de fermento químico e a 3 colheres de sopa de fermento biológico comercial. Enquanto que no comercial a levedura corresponde a aproximadamente $100 \%$ de sua composição, no caseiro ela responde a pequena fração do todo. Assim, o processo de fabricação do fermento apresentou algumas variáveis já previstas, como por exemplo tempo de maturação, visto que dependendo da estação do ano e consequentemente sua respectiva temperatura, esta influência diretamente na multiplicação celular (fase lag/log) (WIN, IMPOOLSUP, NOOMHORM,1996), como o procedimento foi realizado nos meses de janeiro, fevereiro e abril do ano de 2018, as temperaturas estavam na faixa de 28 á $35^{\circ} \mathrm{C}$ (CIIAGRO UNOESTE, 2018), sendo favoráveis a construção do mesmo.

Sobre o tempo para reforma do fermento (FIGURA 1A), este deve ser realizado assim que houver o escape da rolha do frasco onde o fermento for inserido, sendo indicativo de boa atividade microbiana e consequentemente produção de gás, pois neste processo os microrganismos consomem amido e sacarose por meio da glicólise, liberando substâncias como 
por exemplo, etanol (líquido) e dióxido de carbono (gás) e ainda se reproduzindo por brotamento (BRANDÃO E LIRA, 2011; VENQUIRUTO ET AL, 2011). Assim, percebeu-se que a primeira reforma, as quais totalizaram três, não deve ser superior a 24 horas, já que ao iniciar a construção do fermento, é necessário estimular o crescimento das leveduras, através de abundância de nutrientes (substrato) e meio satisfatório (temperatura, número de células/indivíduos e nívies mínimos de toxicidade, nesta última, são substâncias produzidas pelos microrganismos presente ao meio), ou seja, condição que não causem um estresse por competitividade aos nutrientes ofertados ou pela produção de compostos tóxicos ao meio que iniba o ápice de seu desenvolvimento (SOARES, 2005; BYERS, 1981).

Após a confecção do primeiro pão, o fermento pode ser armazenado em geladeira por período de até sete dias, ao passar por esse período é necessário nova reforma mesmo que não se utilize para produção, este fator é para que se mantenha a eficiência do fermento.

\section{Fabricação De Pão Com Fermento Natural De Batata Inglesa}

Na fabricação de pão com fermento de batata inglesa, foi possível constatar a necessidade de maior tempo de descanso para o efetivo crescimento da massa, aproximadamente 11 horas a mais que o fermento químico, pois este se aproxima de 40 minutos. Esse fator é definido pelo clima ambiente, portanto, sendo um empecilho em dias frios. Como o procedimento foi realizado em temperatura ambiente satisfatória $\left(28\right.$ á $\left.35^{\circ} \mathrm{C}\right)$, a massa se desenvolveu conforme o esperado, os valores estão expressos na Tabela 2 e a aparência da massa pode ser visualizada na Figura $2 \mathrm{~A}$ e B. Contudo, para comprovação do ápice do desenvolvimento microbiano, foi esperado um tempo mais longo (cerca de 14 horas), constatando assim que este tempo de descanso não deve ser superior a 12 horas, , pois quando o tempo for superior a este, começa a ocorrer inversão, ou seja, a massa "murcha" pela perda de $\mathrm{CO}^{2}$ produzida deixando a sua estrutura mais porosa conforme destaca a Figura $2 \mathrm{C}$.

Ao mensurar a massa após o tempo de 14 horas, percebeu-se a perda de 2 centímetros de diâmetro, totalizando assim, $33 \mathrm{~cm}$. Mesmo com essa perda de volume o pão foi assado preservando características organolépticas, obtendo ainda sabor e odor agradáveis. A Figura 2D, destaca a massa assada.

Outro fator a ser destacado é que a massa não sofreu ação de cilindro, os quais permitem uma ação mais intensa do fermento, já que como as "dobras" estão mais finas, o gás produzido pelos microrganismos pode "empurrá-las" com maior facilidade, ampliando o seu volume com o respectivo crescimento.

\section{Análises Microbiológicas Do Fermento de Batata Inglesa}

Os resultados das análises microbiológicas apresentaram valores negativos para Bolores, Coliformes Fecais e Salmonella, ou seja, não apresentam microrganismos patogênicos, os quais são proibidos na presença em qualquer tipo de alimento, conforme orienta a ANVISA.

Já a contagem de microrganismos mesófilos totais, que são bactérias comuns ao meio ambiente e possuem faixa de temperatura ótima de desenvolvimento até $40^{\circ} \mathrm{C}$ (STEVENSON, 1974) ficou dentro do esperado, as leveduras analisadas foram identificadas como a espécie Saccharomyces cerevisiae.

\section{CONCLUSÕES}

Com a proposta de fabricação de pão com fermento oriundo de batata inglesa, foi possível avaliar as dificuldades deste tipo de produção, ou seja, verificou-se que há um tempo maior disponibilizado a fabricação e que o controle em assepsia, deve ser tão rigoroso quanto qualquer outro processo fabril. Contudo, este mesmo processo não exige infraestrutura mais complexa do que as já existentes, tornando-se viável. 
Ainda foi possível constatar que o fermento não apresenta contaminantes que prejudicam a saúde humana, além de possuir propriedades organolépticas distintas podendo atrair um público diversificado.

Verifica-se ainda que a indústria de panificação consolida o monopólio dos fermentos químicos e os fermentos biológicos tratados industrialmente. Neste contexto, a proposta de novas formas de realizar a fermentação resgatam um saber empírico que se direciona e explica-se através dos conhecimentos científicos. Mediante a estas informações o fermento natural à base de batata inglesa surge como uma proposta inovadora para o setor de panificação, abrindo portas para a confecção artesanal e um estilo de vida mais saudável.

\section{REFERÊNCIAS}

APLEVICZ, Krischina Singer. Fermentação natural em pães: ciência ou modismo. Aditivos e ingredientes, São Paulo (SP), v. 105, n.11, p. 36-38. 2014. Disponível em: <http://aditivosingredientes.com.br/upload_arquivos/201603/2016030889359001459192809.pdf >. Acesso em: 02 dez. 2017.

BÍBLIA SAGRADA, traduzida em português por João Ferreira de Almeida. Revista e Atualizada no Brasil. 2ed. Barueri-SP: Sociedade Bíblica do Brasil 2011

BRANDÃO, Silvana Soares; LIMA, Hércules De Lucena. Tecnologia de panificação e confeitaria. Técnico em alimentos, Recife, p. 67,68,70,71,72,73. 2011. Disponível em: <http://proedu.ifce.edu.br/bitstream/handle/123456789/366/Tec_Panif_Conf.pdf?sequence=1\&i sAllowed=y>. Acesso em: 07 mar. 2018.

BRASIL. Ministério Da Agricultura, Pecuária E Abastecimento. Secretaria de Defesa Agropecuária (DISPOA). Instrução Normativa $n^{\circ} 62$, de 26 de agosto de 2003. Oficializa os Métodos Analíticos Oficiais para Análises Microbiológicas para Controle de Produtos de Origem Animal e Água. Diário Oficial da União, Brasília, 26 de agosto de 2003. Seção 1

BYERS, B. Cytology of the yeast life cycle. In: STRATHERN, J.N; JONES E.W; broach, J.R., eds. The molecular biology of the yeast saccharomyces life cycle and inheritance. Cold Spring Harbor: Cold Spring Harbor Laboratory, 1981. Part. A, p.59-96.

CIIAGRO ONLINE (Centro integrado de informações agrometeorológicas) - UNOESTE. Disponível em <http://www.ciiagro.sp.gov.br/ciiagroonline/Quadros/QTmedPeriodo.asp> Acesso em: 17 maio de 2018

EMBRAPA. Sistema de produção da batata. Sistemas de produção, [S.L.], v.2, jul. 2016. Disponível em:

<https://www.spo.cnptia.embrapa.br/conteudo?p_p_id=conteudoportlet_war_sistemasdeproduc aolf6_1ga1ceportlet\&p_p_lifecycle=0\&p_p_state=normal\&p_p_mode $=v i e w \& p \_p \_c o l \_i d=c o l u m n-$ $1 \&$ p_p_col_count=1\&p_r_p_-76293187_sistemaproducaoid=8803\&p_r_p_996514994_topicoid=1301>.Acesso em: 06 mar. 2018.

IBGE Levantamento Sistemático da Produção Agrícola. Disponível em <https://sidra.ibge.gov.br/tabela/1618\#resultado> Acesso em: 6 mar 2018

LACAZ, Carlos da Silva $\mathbf{O}$ grande mundo dos fungos, por Carlos da Silva Lacaz, Paulo S. Minami, Adhemar Purchio e outros. São Paulo, Editora da Universidade e Editora Polígono, 1970. 
LACAZ, Carlos Da Silva. Micologia médica: fungos, actinomicetos e algas de interesse médico: fungos, actinomicetos e algas de interesse médico. 8 ed. São Paulo: Sarvier, 1991.

LEONEL, Magali; CEREDA, MarneyPascoli. Caracterização físico-química de algumas tuberosas amiláceas. Ciência e tecnologia de alimentos, São Paulo, v. 22, n. 1, p. 65-69, jan./abr. 2002.

OLIVEIRA, Vanessa Da Gama. Processos biotecnológicos industriais: produção de bens de consumo com o uso de fungos e bactérias.. 1 ed. [S.L.]: Erica - Grupo Somos, 2015. 11, 12, 13, 16, $17,22,25 \mathrm{p}$.

SEBRAE; ABIP. Estudo de tendências: perspectivas para a panificação e confeitaria. Projeto de fortalecimento e oportunidades para micro e pequenas empresas do setor de panificação, biscoitos e confeitaria, p. 10,15, jul. 2009. Disponível em: <http://www.bibliotecas.sebrae.com.br/chronus/arquivos_chronus/bds/bds.nsf/4ac5c034fc7f782 e832576330053107a/\$file/nt0004207e.pdf>.Acesso em: 06 mar. 2018.

SOARES, Fernando Lucas Palhano. Influência da pressão hidrostática em saccharomyces cerevisiae: correlação com estresses químicos e físicos. Vitória, mar. 2005. Disponível em: <http://portais4.ufes.br/posgrad/teses/tese_2680_fernan 1.pdf>. Acessado em: 30 mai 2018

STEVENSON, Greta B. Biologia dos fungos, bactérias e vírus; tradução de Denise Navas Pereira. São Paulo, Polígono, Ed. Da Universidade de São Paulo, 1974.

VENQUIARUTO, L. D. et al. Saberes populares fazendo-se saberes escolares: um estudo envolvendo a produção artesanal do pão. Química e a sociedade, Cidade, v. 33, n. 3, p. 135141 , jul.

<www.educadores.diaadia.pr.gov.br/arquivos/file/.../saber_pop_escolar_art.pdf>.Acesso em: 02 abr. 2018.

WIN, S.S; IMPOOLSUP, A; NOOMHORM, A. Growth kinetics of Saccharomyces cerevisiae in batch and fed-batch cultivation using sugarcane molasses and glucose syrup from cassava starch. J. Ind. Microbiol., Amsterdam, v.16, p.117-123, 1996.

ZAKABI, Rosana. As preferências nacionais. Veja, [S.L.], v. 1959, n. 22, p. 152-153, jun. 2006. Disponível em: <https://acervo.veja.abril.com.br/index.html\#/edition/32528?page=1\&searching=true\&section=1 \&word>.Acesso em: 06 mar. 2018. 